\title{
Selective intrathecal phenol block to improve activities of daily living in patients with spastic quadriplegia. A preliminary report
}

\author{
E Iwatsubo MD, E Okada MD, T Takehara MD, K Tamada MD, T Akatsu MD \\ Labor Welfare Corporation, Spinal Injuries Center, 550-4 Igisu, Iizuka, Fukuoka, \\ 820 Japan.
}

\begin{abstract}
To eliminate severe leg spasms of 15 quadriplegics, $0.3 \mathrm{ml} 10 \%$ phenol-glycerin was injected into the subarachnoid space at the T12/L1 interspace. The effectiveness for leg spasm was evaluated by the Penn spasticity and Ashworth rigidity scales. Three patients remained completely flaccid; however three had slight, six had moderate and three had complete recurrence of spasms in a follow up period of observation for 1 to 22 (average 13) months. The result of selective intrathecal phenol block was significantly valuable, improving the activities of daily living (ADL) of quadriplegic patients. There were no systemic side effects nor disturbance of bladder, bowel or sexual functions.
\end{abstract}

Keywords: intrathecal phenol block; spasticity; quadriplegia; selective nerve block; sparing bladder function.

\section{Introduction}

Excessive muscle spasms often prohibit successful rehabilitation and the urinary care of quadriplegic patients. For good penile hygiene, a condom urinal should be removed during bed time and be replaced by a glass urinal, but this is often overturned by leg spasms. Permanent spinal nerve block to abolish leg spasms of a quadriplegic patient is permissible if bladder, bowel and sexual functions can be spared. In a pain clinic, selective intrathecal phenol injection has been used to obtain localised neurolysis, eliminating cancer pain without impairing ambulatory function. We have applied this technique to control undesirable leg spasms in quadriplegic patients during the past 2 years.

\section{Materials and methods}

Fifteen male patients with spinal cord injury, aged from 19 to 65 (average 36) years, underwent selective intrathecal phenol block to resolve severe leg spasms. Eight were quadriplegic with partial sacral sparing, five were quadriplegic and two were paraplegic without sacral sparing. The patient was placed on the operating table in a recumbent position with his spinal column parallel to the floor. A spinal puncture at the thoracolumbar junction, T12/L1 interspace, was followed by the instillation of $10 \%$ phenol-glycerin. All patients except cases 1 and 15 received $0.3 \mathrm{ml}$ phenolglycerin instillation.

Case 1 received $1.0 \mathrm{ml}$ and case $150.5 \mathrm{ml}$. The patients were kept still for 15 minutes, and were then turned onto their other side for the same procedure on the opposite side. The postoperative neurological state was compared to that of the pre-block state. Spasms of the ileopsoas, quadriceps and adductor femoris muscles were usually abolished. The efficacy of the block was evaluated using the Penn spasticity and Ashworth rigidity scales (Table I) on the following day and on the latest day of the study. The pathophysiological state concerning spasticity and rigidity of these three muscle groups were classified in a score of $1-9$, which is the summation of the former two scales.

\section{Results}

Fifteen spastic quadriplegic males have undergone this procedure (Table II). Twelve had severe spasm of the lower extremities with a score of 9 , one with a score 6 and two with a score 3 . The 
Table I Definitions of Penn and Ashworth scales

\begin{tabular}{ll}
\hline Penn spasticity scale & Ashworth muscle tone scale \\
\hline $\begin{array}{l}\text { Frequency of spasm score } \\
0 \text { No spasms }\end{array}$ & $\begin{array}{c}\text { Degree of muscle tone score } \\
\text { No increase in tone }\end{array}$ \\
1 Mild spasms induced by stimulations & $2 \begin{array}{l}\text { Slight increase in tone, giving a "catch' } \\
\text { when affected part is moved in flexion or } \\
\text { extension }\end{array}$ \\
$\begin{array}{l}\text { Infrequent full spasms occurring less than } \\
\text { once per hour }\end{array}$ & $3 \begin{array}{l}\text { More marked increase in tone, but } \\
\text { affected part easily flexed }\end{array}$ \\
$\begin{array}{l}\text { Spasms occurring more than once per } \\
\text { hour }\end{array}$ & $4 \begin{array}{l}\text { Considerable increase in tone, passive } \\
\text { movement difficult } \\
\text { hour }\end{array}$ \\
\end{tabular}

Table II Selective intrathecal phenol block for spastic quadriplegia

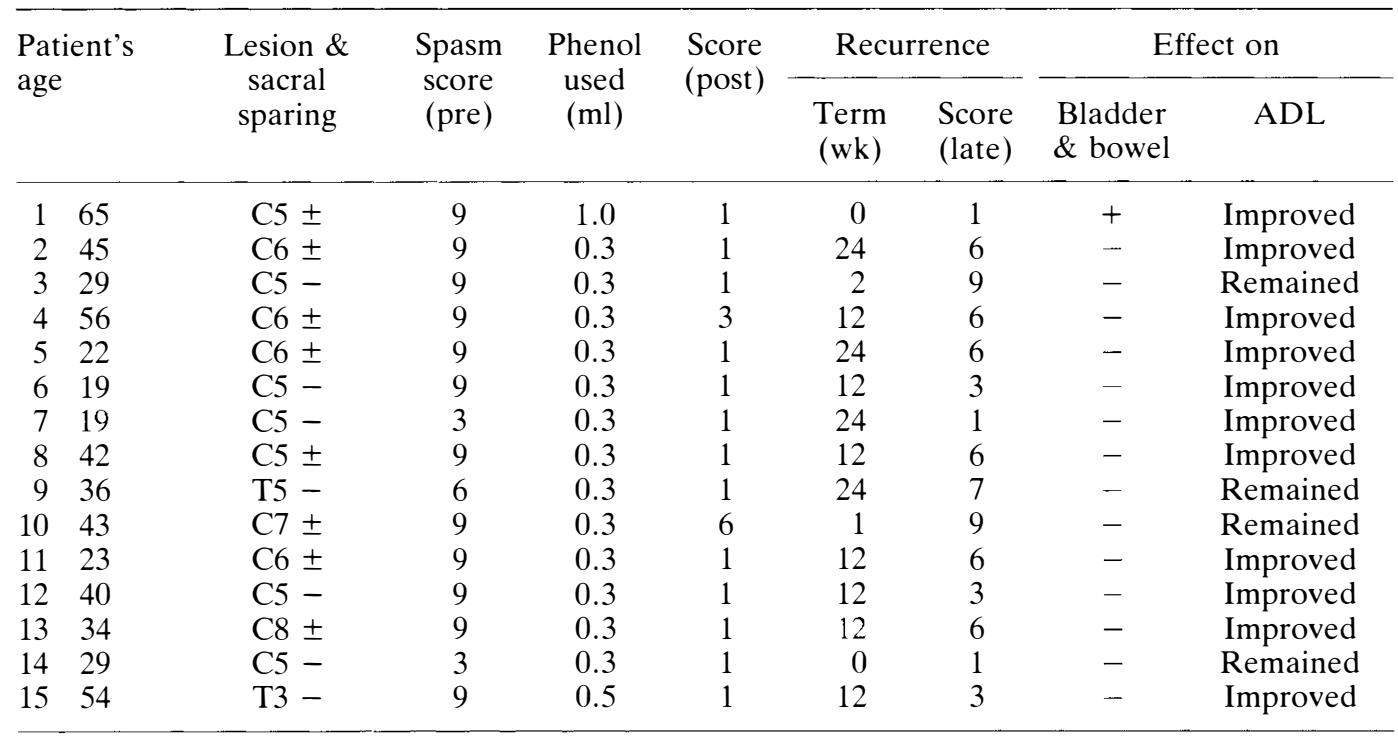

Spasm score $=$ Penn spasticity score + Ashworth rigidity score

$$
\text { (1-9), (0-4), (1-5). }
$$

Sacral sensation: \pm partial sparing; - no sparing.

preoperative average score was $8.0 \pm 2.2$ $(n=15) . \quad 0.3 \mathrm{ml}$ phenol-glycerin caused neurolysis of three or four spinal nerves, usually from L1 to L4 segment levels. Just after instillation, most of the spastic limbs became flaccid. The day after the procedure, the average post score became $1.5 \pm 1.7(n=15)$. The patellar tendon reflex was abolished, but the Achilles tendon reflex and plantar reflex were unchanged. In patients with incomplete lesions, motor function and/or sensation below L5 was noted to be the same as before the treatment and the analgesic area was noted to be in the dermatomes from L1 to L4 (Fig 1). No systemic complication was noted during or after the procedure. Cystometry remained the same as before with hyperreflexia and no bladder, bowel or sexual disturbance except in case 1 whose cystometry showed the bladder to be flaccid (Fig 1). However, spasticity often recurred within 3 months. The late score of spasticity was evaluated at the end of the period of 
a

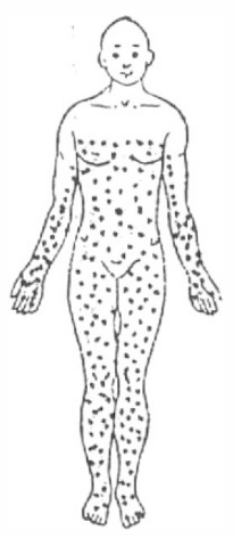

Before
Neurolysis

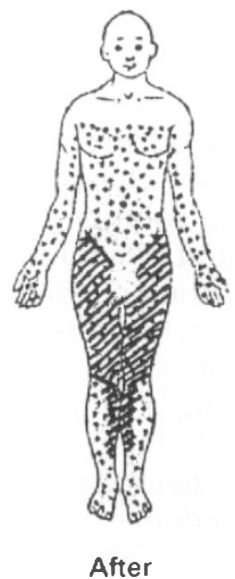

b

Cystometry

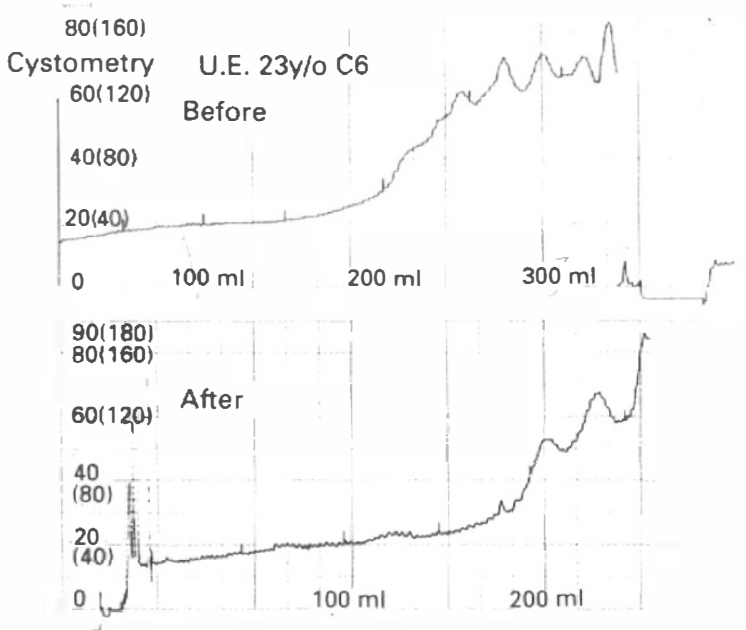

Figure 1 Selective intrathecal nerve block $0.3 \mathrm{ml} 10 \%$ phenol-glycerine at T12/L1. (a) Neurolysis. (b) Cystometry.

observation, from 1 to 22 (average 13) months. Two patients showed a score 9, which means complete recurrence of spasticity, one changed to a score 7 , six to 6 , and three to 3 . The average late score of spasticity was $4.9 \pm 2.7(n=15)$. Significant effectiveness of selective intrathecal phenol injection for spastic quadriplegia was noted between the pre-score and the late score $(p<0.01)$. Self care and assistant care in positioning and transferring of the quadriplegic patients were improved in 11 patients, but there was no improvement in four. The overall results revealed that six were satisfactory, six favourable and three unsuccessful.

\section{Discussion}

Various methods to control spasticity occurring in patients with a spinal cord injury have been tried, often in vain. Muscle relaxants are often insufficient. Epidural infusion of baclofen has only a temporary effect; extradural injection and selective nerve root block at motor points last less than 2 or 3 months. Intrathecal saddle block with phenol-glycerin, which appears to give a long lasting effect has the disadvantage of probably paralysing the pelvic organs. If the procedure can be performed selectively, the functions of pelvic organs may be spared. Harris \& Simpson ${ }^{1}$ discussed the possibility of resolving spasticity in patients with spinal cord damage by surgically painting selected nerve roots with $15 \%$ phenol-glycerin to avoid autonomic bladder dysfunction. He stressed the importance of selective approaches either by anterior rhizotomy or by chemical neurolysis under direct vision, and felt that it was too early to define conclusions about the permanent neurolytic effect of the selective 'painting' procedures. In those days intrathecal needle injection was believed to be inadequate to obtain selective effects on the lumbar nerves and avoiding the pelvic nerves. To decrease complications, Chabal et al $^{2}$ recommended the use of a 22-gauze Teflon-coated needle connected to a nerve stimulator to identify intrathecal spinal roots for neurolysis. He injected a small amount of absolute alcohol. In pain clinics, selective intrathecal phenol injection has been applied to control intractable cancer pain without any side effects. According to a review article by Wood, ${ }^{3}$ intrathecal phenol blocks for spasticity have been reported by Liversedge \& Maher, ${ }^{4}$ Nathan, ${ }^{5}$ and Pederson \& Juun Jensen. ${ }^{6}$ They reported satisfactory results ranging 
from 16 to $92.5 \%$ and a complication rate of urinary dysfunction ranging from 10 to $31 \%$ with $5-10 \%$ phenol instillation. Ichiyanagi ${ }^{7}$ reported the progressive change of phenol and glycerin concentrations in the human subarachnoid space. The mean concentrations of $7 \%$ phenol and glycerin drops rapidly just after instillation and for 15 minutes were $0.1 \%$ and $3.0 \%$, respectively. His data suggest that the clinically recommended time of patient immobilisation to avoid side effects with phenol ranges from 15 to 60 minutes. Iijima ${ }^{8}$ reported the correlation between the spinal interspace to be punctured and the spinal nerve segments to be neurolysed. Thoracic and lumbar nerve segments locate at the 2.4 and 4.5 interspaces above the corresponding vertebra, respectively. The estimated amount of phenol-glycerin to be used for neurolysis of one segment is $0.229 \pm 0.118 \mathrm{ml}$. In our experience, $0.3 \mathrm{ml}$ instillation of $10 \%$ phenol-glycerin at the level of the T12/L1 interspace affected the spinal nerve segments from L1 to L4. Differences in the amount of phenol-glycerin for effective neurolysis between an analgesic and an antispastic effect seem to depend on the position of the patient and the characteristics of nerve fibres contributing to these hazards. The results of neurolysis may depend on the location of the needle tip ${ }^{9}$ and the characteristics of the phenolglycerin solution. ${ }^{10}$ Selective intrathecal injection of phenol-glycerin with much higher concentration, using a Teflon-coated needle with electrical stimulation to identify the location of the needle may be valuable in obtaining a more lasting antispastic effect. Harris \& Simpson ${ }^{1}$ introduced the findings of the neuropathologist that the roots of cauda equina showed degeneration only on the outside of the bundles, while the autopsy of a patient who had undergone phenol and alcohol blocks some years previously showed that the inside was apparently untouched. This may suggest the reason for some limitations of the permanent effects of chemical neurolysis; however this is not yet fully known.

\section{References}

1 Harris P, Simpson JA (1963) A new technique for the use of phenol to control spasticity and spasms. Paraplegia 1: 197-198.

2 Chabal C, Jacobson L, White J (1989) Electrical localization of spinal roots for the treatment of spasticity by intrathecal alcohol injection. Anesthesiology 68: 527-529.

3 Wood KM (1978) The use of phenol as a neurolytic agent: a review. Pain 5: 205-229.

4 Liversedge LA (1960) Use of phenol in relief of spasticity. BMJ 2: 31-33.

5 Nathan PW (1965) Chemical rhizotomy for relief of spasticity in ambulant patients. BMJ 1: 1096-1100.

6 Pedersen E, Juun-Jensen P (1965) Treatment of spasticity by subarachnoid phenol-glycerin. Neurology (Minneap.) 15: 256.

7 Ichiyanagi K, Matsuki M, Kinefuchi S, Kato Y (1975) Progressive changes in the concentration of phenol and glycerin in the human subarachnoid space. Anesthesiology 42: 622-624.

8 Iijima K, Sumida M, Izawa E et al (1987) Relationships between the level of intrathecal puncture point and the analgesic area in subarachnoid phenol blocks. Pain Clin 8: 203-208.

9 Fudeta H, Takahashi S, Kaneko $\mathrm{T}$ et al (1983) Neurolytic effect and puncture needle position in subarachnoid phenol block. Clin Anesthesiol 7: 758-762.

10 Kitajima T, Kin H, Yoshinaka A et al (1981) Intrathecal phenol block and quality of phenol in glycerin. J Pain Clin 2: 173-179. 